\title{
O povedkovniku oziroma povedkovniškosti
}

\author{
Andreja Žele
}

\begin{abstract}
Prispevek ima namen z opredelitvami in sklepi povzeti in skleniti vse dosedanje ugotovitve različnih domačih in tujih jezikoslovcev v trditev, da je povedkovnik ubesedena skladenjska kategorija s stalno in zato tipično skladenjsko vlogo za glagolskim pomožnikom - v zloženem povedku je povedkovnik pomenonosna sestavina. S slovaropisnega vidika bi bila ta povedkovniška vloga lahko predstavljena z oznako povdk.
\end{abstract}

\section{The Predicative, or the Predicative Role of Words}

This article summarizes all previous conclusions and findings by various linguists from Slovenia and abroad into the claim that the Slovenian predicative (povedkovnik) is in fact a lexicalized syntactic category with a fixed and therefore typical syntactic role in combination with the auxiliary verb; it represents a semantic component in a predicator. From the lexicographic perspective, this predicative function might be represented with the label povdk.

0 Že dosedanje obravnavanje povedja oz. njegovih sestavin vodi v smer opredelitve povedkovnika kot »zgolj« skladenjskopomenske kategorije in ne samostojne besedne vrste. ${ }^{1} \mathrm{~V}$ tem smislu je mogoče povedkovnik imenovati tudi povedkovniškost. $\mathrm{V}$ zloženem povedku je ta slovnična kategorija kot nujna pomenonosna kategorialna pomenska sestavina ubesedena ob pomožnikih oz. pomensko izpraznjenih glagolih, izrazijsko kot pomožnik + povedkovnik = povedek. Tako s stavčnočlenskega kot z izrazijskega vidika je smiselno govoriti o povedkovniku (prim. z nedoločnik/namenilnik v povedku), ker so določila in dopolnila izrazijsko zasedena pri vezljivosti in družljivosti udeležencev.

\subsection{Namen}

Zaradi neobvezne vključenosti katere koli izmed slovničnih kategorij, ki so sicer tipične za posamezne besedne vrste, je še najustrezneje, da povedkovnik opredeljujemo kot pomenskoskladenjsko kategorijo (v tuji strokovni literaturi je uveljavljena kategorija predikativnosti) oz. kategorijo povedkove rabe oz. kot povedko-

1 Povedkovnik je najustreznejši jezikoslovni izraz za skladenjsko kategorijo tako na pomenskoskladenjski kot na strukturnoskladenjski oz. izrazni ravni tudi zato, ker povedkovniki ne določajo drugih samostojnih stavčnočlenskih besednih vrst, in tudi ne pojasnjujejo njihovih lastnosti (kot to delajo pridevniki in prislovi). 
vo kategorijo stanja/lastnosti. Funkcijskost povedkovnika, in ne (še) besednovrstnost (povedkovnik je torej vmesna stopnja leksikalizacije $\mathrm{v}$ drugotne/metaforične pomene), posredno potrjuje povedkova vezljivost $\mathrm{s}$ tem, da pomenskoskladenjske zmožnosti povedkovnika (stanjskost, dejanjskost ali posledično lastnost) veže na povedkovo vlogo - $\mathrm{v}$ češkem jezikoslovju, ki nam je zaradi sistemske podobnosti slovenščine in češčine najbližje, je to opredeljeno kot 'komplementarna obligatorna determinacija'. V naši strokovni literaturi (predvsem v SS 1976, NSS 1982, ESJ 1992 in SLP 2000) so večkrat ponovljeni pomisleki glede besednovrstnosti povedkovnika posredno izraženi z opredelitvami kot zelo obsežna in pomensko heterogena besedna vrsta, stranski stavčni člen, samo skladenjskofunkcijska opredelitev zrelativizira merila besednih vrst in hkrati stalnost skladenjske vloge omogoča/zagotavlja odprto rabo drugih besednih vrst. ${ }^{2}$ Slovarsko naj bi bile besede v povedkovni rabi oz. povedkovniški rabi z oznako povdk. navadno izpisane kot podgesla (kar ustreza preneseni pomenski rabi geselskih leksemov), izjema je le nekaj prvotno besednovrstno neopredeljenih besed, razvojno verjetno besednih krnov, tipa všeč, žal, prav, treba ipd., ki navadno so oz. naj bi bile samostojna gesla.

\section{Opredelitve}

- Aktualna trenutna stanjskost je $\mathrm{v}$ slovenščini navadno izražena z zloženim povedkom - prvotna povedkova raba namreč izpostavi samo določene pomenske sestavine, saj povedkovniki niso nič drugega kot pomenske determinante povedkov. Priložnostna pomenskoskladenjska raba ne more biti besednovrstno odločilna, zato povedkovniki, za katere je odločilna povedkov(nišk)a raba, ostajajo na stavčni ravni s poimenovalnimi različicami povedkovo dopolnilo $>$ povedkov dopolnilnik > povedkovnik. ${ }^{3}$ S pomensko-izraznega vidika je povedkovnik pomenskoskladenjska kategorija oz. kategorialni sem/semem, ki pomenskoskladenjsko dopolnjuje glagole $\mathrm{v}$ povedku, in hkrati strukturnoskladenjska kategorija, izrazno opredeljena kot zgradbeni označevalnik.Tako funkcijska kot pretvorbena slovnica potrjujeta povedkovnik kot skladenjskopomensko kategorijo (in ne še besedno vrsto). Posredno zanikanje besednovrstnosti povedkovnika je tudi (vsaj občasno) vztrajanje, da med povedkovnike sodita tudi opisna deležnika in nedoločnik. Kljub deklarirani povedkovniškosti pa se da tudi besede (oz. razvojno gledano besedne krne) kot všeč, mar, žal, mraz, tema, škoda, dolgčas (vsaj razvojno) slovarsko besednovrstno opredeliti kot samostalnike, žal tudi kot pridevnik, tiho, prav, lahko kot prislove, lahko, treba tudi kot členke ipd.

2 Tu mislim predvsem na Slovensko slovnico (SS 1976: 412, 594-595), Novo slovensko skladnjo (NSS 1982: 116-117, 407) in Enciklopedijo slovenskega jezika (ESJ 1992) Jožeta Toporišiča ter na oceno Nove slovenske skladnje Jožeta Toporišiča (Vidovič Muha 1984: 142-155) in Slovensko leksikalno pomenoslovje (SLP 2000: 30-33, 38, 63, 188) Ade Vidovič Muha.

3 Češko jezikoslovje je potrdilo povedkovnik kot skladenjskopomensko kategorialno sestavino z izrazom 'obvezni določevalni dopolnilnik', kar je bilo v naši strokovni literaturi komentirano v začetku sedemdesetih let (Pogorelec 1972, 1974). 
- Povedkovniki (ob pomožnikih; povedek = pomožnik + povedkovnik) so glede na izključno prvenstvenost povedkove skladenjske vloge lahko prvotni ali drugotni. Skupna lastnost povedkovnikov je, da pomenijo stanje ali lastnost, (dejavno)vezljivi oz. kot nosilci vezljivosti povedkovniki izražajo različna razmerja oz. odnose. Od tipičnih inherentnih glagolskih kategorij je poleg vezljivosti ohranjen tudi naklon.

- Povedkovniki ne določajo oz. opredeljujejo drugih besednih vrst, in tudi ne pojasnjujejo njihovih lastnosti (kot to delajo pridevniki in prislovi). Čeprav imajo nekatere značilnosti prislovov (tj. navadno so nepregibni, le da se povedkovniški prislovi lahko stopnjujejo), povedkovniški pridevniki pa se lahko pregibajo še po spolu in številu, se vežejo le z vezjo ali s skladenjskopomensko oslabljenimi glagoli, in zato ne morejo pojasnjevati pomensko samostojnih glagolov in pridevnikov - ne prevzemajo kategorij od jedrne besede, temveč si kategorije s pomožnikom porazdelijo.

\subsection{Slovarsko označevanje}

Povedkovniki oz. povedkovniške rabe so v Slovarju slovenskega knjižnega jezika navadno označeni s kombinacijami slovničnih pojasnil kot neskl. prid., v povedni rabi in prisl., v povedni rabi, in še v povedno-prislovni rabi, kar bi se lahko poenotilo v oznako povdk. v smislu povedkovniške rabe oz. povedkovniškosti kot kategorialne skladenjskopomenske lastnosti. Sicer pa so vsaj posredni pokazatelji za potencialno povedkovniško rabo tudi slovarske oznake za preneseno rabo besed. Preneseni pomen je navadno označen z ekspr(esivno) oz. slabš(alno), vulg(arno) ali ljubk(ovalno), ni pa npr. v SSKJ označena slabšalna (vulgarna) in ljubkovalna raba živalskih poimenovanj v zvezi s človekom, ko zaradi metaforičnosti dosledno prihaja do spremembe uvrščevalne pomenske sestavine, npr. Tako je pri živalskih poimenovanjih v povedkovniški rabi prevladujoča uvrščevalna pomenska sestavina človeško ${ }^{+}$, npr. On (UPS = človek) je tič/tičko (RPS = iznajdljiv, prebrisan), Ona $(\mathrm{UPS}=$ ženska) je tička $(\mathrm{RPS}=$ mlada, ljubka); Ta človek $(\mathrm{UPS})$ je prava kača $(\mathrm{RPS}$ = hudoben, zahrbten) ipd.; ${ }^{4}$ še s slovarsko oznako vulg(arno), tako da je uvrščevalna pomenska sestavina (UPS) upoštevana v označevani osebkovi besedi, razločevalne pomenske sestavine (RPS) pa so kot prisojevalne lastnosti vključene v označevalno povedkovodoločilno oz. povedkovniško besedo, so npr. Ta človek (UPS) je čisto navadna rit (RPS = neznačajen, bojazljiv), Ta človek (UPS) je navadna goflja $(\mathrm{RPS}=$ prezgovoren, predrzen) ipd.

${ }^{4} \mathrm{O}$ t. i. slovarskih uvrščevalnih in razločevalnih sestavinah je pri nas pisala A. Vidovič Muha (1988: 26-27). A. Vidovič Muha (2000: 31) govori o »spremembi kategorialnih lastnosti [...], ki povzroči prehod ene besedne vrste v drugo [...] «. Ista avtorica pri metaforičnih pomenih govori o nanovo dodanih razločevalnih pomenskih sestavinah (RPS), ki se opomenijo na skladenjskofunkcijski ravni v novi denotat ali pa ostanejo samo na skladenjskofunkcijski (konotativni) ravni in se ne leksikalizirajo (Vidovič Muha 2000: 85-109), npr. za leksem človek ugotavlja, da v povedkovodoločilni vlogi s pomenom 'human, človeški' lahko vedno tvori lastnostne stavke - iz tega posledično potrdi upravičenost kategorialne pomenskosestavinske oznake povedkovnik za tovrstne lekseme tudi v slovarjih (Vidovič Muha 2000: 125). 
V Slovenskem pravopisu je registriranih kar 458 kvalifikatorjev povdk. ali povdk. zv(eza), gl. Krajšave in slovarske oznake, str. XIV).Vsi izpisani primeri z različnih vidikov potrjujejo oznako povdk. kot pomenskoskladenjsko kategorijo. Čeprav je povedkovnik v SP-ju eksplicitno (tudi v komentarju Spremne besede na str. VIII) predstavljen zgolj kot iztočnica/geslo, in nikoli kot podiztočnica/podgeslo, ga kot skladenjskopomensko kategorijo in hkrati - posledično kot oznako za povedkovniško vlogo potrjuje tudi skupni naslov Prislovi, povedkovniki in zveze z njimi (62) v Pravilih I in definicija (204). Posredna potrditev povedkovnikov kot skladenjskopomenske kategorije (in ne že kot besednovrstne kategorije) je nakazana tudi s potenčno številko ob geselski besedi, ki v primerih povedkovnika navadno opozarja na neprvo oz. drugotno skladenjskopomensko uporabo določenega leksema.

\subsection{Primerjalno v tuji literaturi}

Najpomembnejše je torej položajsko merilo - pri povedkovniku se ta pomenskoskladenjska kategorija prekriva s kategorijo predikativnosti - v slovanskem jezikoslovju tudi jezikoslovnoizrazijsko uveljavljena t. i. kategorija predikativnosti. ${ }^{5}$ Iz ruskega jezikoslovja »kategorija sostojanija«, po A. V. Isačenku (1954: 255) t. i. »kačestvennoe sostojanie«, ruska jezikoslovna literatura pri opredeljevanju ostaja samo na skladenjskopomenski ravni - govori samo o predikativni vlogi, predikativnem členu in o predikativni kratki obliki pridevnika. Tudi slovaška skladnja rapravlja samo o imenskem delu povedka (1966), ravno tako hrvaška skladnja (Katičić 1986). Češka slovnica (1986, 1987, 1996, 1998, 2001) uporablja samostojno poimenovanje predikativ, ki ga znotraj povedja oz. povedka opredeljuje samo kot kategorijo stanja »kategorie stavu« in izraze kot samostalniški predikativ, pridevniški predikativ ipd., pa tudi imenski del / izraz glagolsko-imenskega povedka - ıjmenná část / jmenný výraz slovesně-jmenného predikátoru«. Poljska slovnica (Gramatyka 1984) uporablja 'predikativno vlogo' ali najpogosteje kar oblikovno-izrazno 'povedkov izraz' (»funkcja predykatywna«, »W funkciji orzecznika«, »wyrażenie predykatywne«). Nemška slovnica (Helbig Buscha 1984) uporablja zveze »der attributive Gebrauch« in »der prädikative Gebrauch«. Angleško in ameriško jezikoslovje predikative samo skladenjskopomensko opredeljuje kot »predicative noun « in »predicative adjective«, in še »predicative nominal« in »predicative adjectival« (prim. Quirk idr. 1993: 354; Quirk 1994: 505, 1174).

\section{Tipologija rabe}

Z vidika razločevanja besednih vrst v povedkovniški vlogi so najštevilčnejši a) povedkovniški pridevniki (pregibanje po spolu in številu in stopnjevanje), kar glede

5 Ruska slovnica (Švedova idr. 1980) predikativnost opredeljuje kot skladenjsko kategorijo (86), v zvezi s tem so izpostavljena 'formalno-semantična razmerja' (372). Sploh pa je v slovanskem jezikoslovju tudi jezikoslovnoizrazijsko uveljavljena t. i. kategorija predikativnosti, prim. Simeon (1969: 641). Češka slovnica (Grepl idr. 1986: 195) sicer uporablja samostojno poimenovanje 'predikativ', vendar ga znotraj povedja oz. povedka opredeljuje samo kot 'kategorijo stanja' - »kategorie stavu«. 
na tipično pridevniško stanjskost ne preseneča. a) Vezljivi izglagolski so: deležen (česa), dolžen (komu kaj) ipd.; prostomorfemski: blazen od, bolan od, dober zal kot ipd. $\mathbf{a}_{2}$ ) Nevezljivi neizglagolski so: domač, godov (nar.), ljudski ipd.; nepregibni: *ad acta, fair, flegma, fuč ipd. Sledijo b) povedkovniški prislovi (z možnostjo stopnjevanja): bot, dolgčas/predolgčas, larifari, *kvit, mar ipd., in naklonski (ki pogosto vežejo tudi nedoločnik): gotovo, mogoče/nemogoče, možno ipd. c) povedkovniški samostalniki (z možno pregibnostjo po številu) so pretežno izglagolski, npr. navada, sram, škandal, škoda/preškoda, utopija, zakon; prostomorfemski: reklama za; z nedoločnikom: užitek, veselje. $\mathbf{c}_{\mathbf{1}}$ ) Neizglagolski so: vezljivi: kos (komu/čemu), last (koga/česa), in nevezljivi: fakt, *basta/konec ${ }^{k / \check{c}}$, luksuz. č) Samo povedkovniki so npr. všeč, prav, dolgčas/predolgčas, mar, mraz, okej, sram, škoda, tema v Vse mi je všeč, Tako je prav, Dolgčas/Predolgčas mi je, Otroci ji niso mar, Zunaj je bil(o) mraz, S stanovanjem je vse okej, Sram ga je pred starši, Te obleke je škoda, Bil-a/-o je še tema; povedkovniki so lahko še izglagolski medmeti kot stavčni členi, npr. To bo joj/prejoj, in sklopi tipa boglonaj, bogpomagaj, bogve, ker je za njih tipična povedkovodoločilna vloga in so zaradi svoje tvorjenosti tudi sicer besednovrstno nejasni. Naklonski izrazi tipa rad-a-o in lahko imajo kot glagolski modifikatorji v povedku več skladenjskopomenskih možnosti, npr. biti lahko : lahko delati, biti rad doma : rad delati : imeti rad vse, biti treba : treba delati.

\section{Primeri povedkovniških pridevnikov}

Tako pomensko premaknjena/prenesena kot (slovarsko označena) široka in oslabljena raba izražajo večjo navezanost na povedkovn(išk)o rabo in hkrati tudi višjo stopnjo povedkovniškosti tako označenih pridevniških besed:

čuden 'ki se v vedenju, ravnanju razlikuje od drugih': Po nesreči je postala nekam čudna, Čuden je, ne morem ga razumeti, (ekspr.) Ne bodi no čuden, daj si dopovedati;

divji (ekspr.) 'zelo jezen': Kmalu se vrni, sicer bo oče divji;

dober 'ki glede na kak kriterij, normo, zahtevo ustreza, zadovoljuje': Pritisk imate dober;

dober 'veljaven, uporaben': Voz ni več dober;

dober 'ugodno vpliva, koristi': Počitek je dober;

dober (pog., s širokim pomenskim obsegom): Ta bo dober;

domač 'ki ne kaže strahu v občevanju z ljudmi': Že čez nekaj dni je postal domač; edin (dv. in mn.) 'ki je enakih misli, istega mnenja': Bili so (si) edini;

$\mathrm{R}$

vesel (nav. z rodilnikom) 'ki občuti veselje, zadovoljstvo ob čem': Vesel je bil darila/gostov;

vreden 'ki zaradi svojih lastnosti, navadno dobrih, pozitivnih, zasluži kaj': Je vreden ljubezni/spoštovanja;

želen (z rodilnikom) 'ki ima (veliko) željo po čem’: Bil je želen dela/dobrih jedi; 
- $\quad \mathrm{R}_{\mathrm{od} / \mathrm{do}}-$ razmernostanjski duševnostni pomen:

저 fair / fair do 'ki je v skladu z določenimi normami, pravili': On je fair, Bil je vedno fair do nje;

hladen / hladen do 'ki vsebuje, izraža nenaklonjenost, odklanjanje': Ta človek je hladen, Bil je hladen do gostov;

$\mathrm{D}$ dorasel (z dajalnikom) 'ki je kos čemu': Mladina je dorasla delu/nalogam; drag (z dajalnikom) 'do katerega ima kdo pozitiven čustven odnos': Ta človek mu je zelo drag;

enak ( $\mathrm{z}$ dajalnikom) ' $\mathrm{ki} \mathrm{v}$ primerjavi drugega $\mathrm{z}$ drugim nobeden nima prednosti, večjih pravic': Njegov uspeh je enak ničli, Lira je enaka dvema tolarjema;

$\mathrm{D}+\mathrm{T}$

dolžen 'ki je obvezan komu kaj izkazovati, storiti': Dolžen sem mu hvaležnost;

$\mathrm{T}_{\text {naza }}$-razmernostanjski/-tvorni pomen z/namenskostjo/ciljnostjo/:

divji / divji na (ekspr.) 'zelo jezen': Ves je divji / Nanj je ves divji;

dober / dober za 'ki glede na kak kriterij, normo, zahtevo ustreza, koristi': biti dober / biti dober za koga/kaj/kam/za koliko časa;

$\mathrm{M}_{\mathrm{v} / \text { pri/na/po }}$-okoliščinskost (prostorsko-časovna/duševnostna):

izveden $v$ 'ki kako stroko, dejavnost dobro obvlada': Je izveden v državniških zadevah;

navzoč pri/na (z oslabljenim pomenom) 'ki je v določenem času na določenem mestu': Inšpektor je bil navzoč pri pouku matematike, Na sestanku so bili navzoči vsi člani;

znan po 'ki vzbudi v osebku občutek identičnosti s tem, kar pozna, ve': Znan mi je le po obrazu;

$\mathrm{O}_{z / s}$-razmernostanjski duševnostni pomen:

domač / domač z/s / domač pri 'ki ne kaže strahu v občevanju z ljudmi': biti domač / biti z njim čisto domača / biti domač pri kom;

mehek / mehek z/s (ekspr.) 'obziren, popustljiv, prizanesljiv': Predstojnik je bil sumljivo mehek, Upravnik je bil mehek s kaznjenci ...

3.1 Možni skladenjskopomenski prehodi iz tvornega dejanja $\mathrm{v}$ povedkovniško stanjskost in nato $\mathrm{v}$ prilastek so najbolj jasno izraženi pri deležnikih na $-l .{ }^{6} \mathrm{~V}$ okviru homonimije tvornega deležnika na $-l$, deležnika stanja na $-l$ in iz njega sprevržnega (drugotnega) lastnostnega pridevnika na -l se lahko stavčnopoložajsko in skladenjskopomensko izločijo potencialni povedkovniki na -l, nevezavni, npr. zmrzel: Zemlja je še zmrzla 'ki je zmrznjena' nasproti: zmrzel: (ekspr.) Je preveč zmrzla 'ki jo rado pogosto zebe'; zrel: Pšenica/Deklica je že zrela 'ki v rasti, razvoju doseže

6 Bajec (1952: 48-49) za deležnike na - $l$ trdi, da se »cela vrsta deležnikov že čuti za pridevniške ali pa so na meji med obojim pomenom«. S tem avtor posredno potrjuje povedkovniškost deležnikov na -l, npr. dorasel, izbokel, narasel, obledel, odebelel, otrpel, ozebel, trhel, vrel, zamolkel ipd. 
stopnjo, primerno za spravilo, razmnoževanje', Fant je zrel 'ki je telesno in duševno polno razvit' nasproti: zrel za: Otrok je zrel za šolo 'ki je sposoben za kaj', Žival je zrela za zakol 'ki je primeren za kaj', 'ki ima ustrezne pozitivne in negativne lastnosti za kaj’ Knjiga je zrela za tisk; (ekspr.) Fant je zrel za zapor, Stolp je zrel za rušenje.Vezavnost samo še utrjuje in potrjuje njihovo povedkovniškost.

V Slovarju slovenskega knjižnega jezika (SSKJ) so to geselske iztočnice $\mathrm{s}$ slovničnim kvalifikatorjem prid(evnik) in geselske podiztočnice v okviru glagolskih gesel.

3.1.1 Posebna skupina so povedkovodoločilni deležniki stanja iz dovršnih (zelo redko nedovršnih) neprehodnih in pretežno povratnih glagolov (osebkov udeleženec je hkrati povzročitelj in nositelj stanja) - zaradi dovršnosti in neprehodnosti/ povratnosti izhodiščnega glagola (posledica slednjega je samo osebkov udeleženec) so pretvorbe v stanjskost in naprej v popridevljenje najbolj jasne, npr. ohripel: Glas mu je ohripel; ohromel: (pren.) Njegova volja je polagoma ohromela; okamnel: Pred poveljnikom je stal kot okamnel; okorel: Sklepi so okoreli; okrnel: Popki so okrneli; oledenel: Vrh/Pogled je oledenel; olesenel: Obstal je kot olesenel; omedlel: Našli so jo omedlelo; omrtvel: Deli telesa so omrtveli; onemel: Onemel je obstal pred očetom; onemogel: Postal je onemogel, Onemogel je od dela; zasedel: Noga je zasedela, nasproti: zaseden: Sedeži so zasedeni, (pog.) Ta teden je zaseden; ipd. ${ }^{7}$

Prevladujoča povedkovodoločilna raba in z njo povedkovniškost izpostavi stanjskost s posledično lastnostjo:

znàn/znán - 'ki obstaja': Afera je že splošno znana; še eno- ali dvovezavni primeri, ki iz obstajanja izpeljujejo tudi lastnost ( $>$ izraženo je z obvezno predmetno vezavo ali z neobvezno prislovnodoločilno vezavo): Ti običaji so znani na kmetih, Kraj je znan po marmorju, Znan mi je le po obrazu, Bil je znan z vsemi veljaki; poznàn/poznán - 'za katerega obstajanje, lastnosti se ve': Nikomur poznan človek,

Ti problemi so mi poznani; podobno potrében: Potreben je denarja, Zelo mu je potreben; pózitiven/pozitíven: Izid preiskave je pozitiven;

Naklonskost povedkovnikov uvaja tudi vezavnost (npr. neobveznovezavni rodilnik $\left.\left(\mathrm{R}_{\mathrm{do}}\right)\right)$ :

pozóren - 'izraža skrb, zavzetost za koga': Vedno je pozorna do njega;

pravičen - 'ki ravna v skladu z določenimi normami, načeli': Je pravičen do sose$\operatorname{dov} \ldots$

3.2 Z besedotvornega vidika pridevniški sklopi z nikalnico ne- in pridevniške sestavljenke s pre- ('preveč') nakazujejo izhodiščno podstavo v povedku, npr. neumen: 'ki ne ravna v skladu $\mathrm{z}$ razumom, pametjo' - Mlad je še in neumen, 'ki ni

7 Sicer pa o izvornosti pridevnikov oz. predvsem o »izgubi prvotnega participialnega pomena« in o "pridobitvi pridevniškega« piše Bajec (1952: 29, 36, 42, 48) in ugotavlja, da so »deležniki često postali pridevniki in to je jezik tudi na zunaj izrazil s tem, da jim je dodal ekspletivni formant -ən« (Bajec 1952: 42). 
sposoben hitro dojemati, prodorno misliti' - Preveč je neumen, (ekspr.) 'neprimeren, neustrezen' - Te pentlje na obleki so prav neumne; nepomemben: (ekspr.) 'ki ni pomemben' - Pri tem delu se jim je zdel nepotreben in nepomemben, (knjiž., ekspr.) 'majhen, neznaten' - Količina se jim je zdela nepomembna; predebela: 'ki je preveč debela' - Ta knjiga/ženska je predebela, (ekspr.) 'ki je zelo pretirana, neverjetna' - Novica je predebela; prepičel: (nav. ekspr.) 'ki je preveč pičel' - Hrana je prepičla. Poleg tega pridevniške sestavljenke s predponskim obrazilom odpirajo desno vezljivost.

\section{Povedkovniška kategorija $\mathrm{z}$ vidika pomenske širitve leksemov: - čist} fant : Fant je čist (1. 'ni umazan', 2. 'moralno neoporečen', 3. 'nedrogiran') in podobno še v primerih, ko povedkovniška raba uvaja več novih pomenov: okrogel fant - Fant je okrogel ('debel', 'pijan/vinjen'), ta težek človek - Ta človek je težek ('z veliko težo', 'ki se ne da prepričati' oz. 'zapletenejšega značaja'), dobra ženska - Ženska je dobra ('dobrosrčna/dobrodušna', 'zdrava', 'prijetnega nadpovprečnega videza'), domač človek - Človek je domač ('biva v istem domu/okolju', 'priljuden in naravnega obnašanja'), ljudski mož - Mož je ljudski ('biti iz ljudstva', 'priljuden'); nasproti npr. ruknjen človek, sesut človek, kjer je povedkova raba tipičnejša od prilastkove, npr. Ta človek pa je malo ruknjen ('nenavaden, poseben'). Pomensko zlitejše stalne stave so posebnost v smislu, da načeloma ne dopuščajo smiselne rabe istih sestavin tudi v povedku, npr. prava reč : prava stvar (smiselno je Stvar je prava), prava figa, čista resnica. Z vidika pomenskosti biti je treba opozoriti še na primere kot Vprašanje/Zadeva je mimo (pomensko oslabljeni biti, ki še ohranja časovni pomen) : Obleka je mimo (vezni biti) ipd.

\section{Sklepna opredelitev}

Povedkovnik je skladenjskopomenska kategorija, ker je samo pomensko-zgradbena sestavina povedka s stalno in edino skladenjsko vlogo v povedku in povedkovniškost je njegova nosilna skladenjskopomenska lastnost. Tudi izraz oz. oznaka povedkovnik je primeren (primerjaj npr. nedoločnik, namenilnik) s tudi že uporabljano krajšavo povdk. Prvotna povedkovniškost kot kategorija oz. prvotna povedkovniška skladenjskopomenska vloga je kot glavna razločevalna kategorialna lastnost/sestavina tipična le za majhno množico razvojno zelo heterogenih (navadno besednovrstno neopredeljenih) besed oz. besednih krnov kot všeč (iz všečen), mar (iz maren), žal (iz žaliti), mraz (iz mraziti), treba (nam. potrebovati), škoda (nam. škoditi), dolgčas (dolgočasno), prav (pravilno), lahko in z leksikografsko-leksikološkega vidika samo te lahko nastopajo kot samostojna povedkovniška gesla z oznako povdk., medtem ko bi dovolj pogosta/tipična (drugotna) povedkovniška vloga pri besednovrstno različnih geslih lahko bila predstavljena v povedkovniških podgeslih, tudi z oznako povdk. 


\section{Viri in literatura}

Bajec 1952 = Anton Bajec, Besedotvorje slovenskega jezika 2: Izpeljava slovenskih pridevnikov, 3: Zloženke, Ljubljana: SAZU, 1952.

Čechová 1996 = M. Čechová idr., Čeština - ̌reč a jazyk, Praha, 1996.

Čermák 2001 = František Čermák, Jazyk a jazykověda: Přehled a slovníky, Praha: Nakladatelství Karolinum, 2001.

ESJ 1992 = Jože Toporišič, Enciklopedija slovenskega jezika, Ljubljana: Cankarjeva založba, 1992.

Gramatyka 1984 = Gramatyka współczesnego języka polskiego: Morfologia, Składnia, Warszawa, 1984.

Grepl - Karlík 1998 = M. Grepl - P. Karlík, Skladba češtiny, Votobia, 1998.

Grepl idr. 1986-1987 = M. Grepl idr., Mluvnice češtiny 2: Tvarosloví, 3: Skladba, Praha: Academia, 1986, 1987.

Helbig - Buscha 1984 = Gerhard Helbig - Joachim Buscha, Deutsche Grammatik, Leipzig: VEB Verlag Enzyklopädie, 1984.

Isačenko 1954-1960 = A. V. Isačenko, Grammatičeskij stroj russkogo jazyka v sopostavlenii s slovackim: Morfologija 1-2, Bratislava: Izdavatel'stvo Slovackoj akademii nauk, 1954-1960.

Katičić 1986 = Radovan Katičić, Sintaksa hrvatskoga književnog jezika, Zagreb, 1986.

Morfológia 1966 = Morfológia slovenského jazyka, Bratislava: Vykladatel'stvo Slovenskej akadémie vied, 1966.

NSS 1982 = Jože Toporišič, Nova slovenska skladnja, Ljubljana: DZS, 1982.

Pogorelec 1972 = Breda Pogorelec, Dopolnilnik (povedkov prilastek) v slovenski skladnji, Linguistica 12 (1972), 315-327.

Pogorelec 1974 = Breda Pogorelec, Dopolnilnik (povedkov) v slovenski skladnji, Jezik in slovstvo 20 (1974), št. 5, 120-122.

Quirk 1994 = R. Quirk, A Comprehensive Grammar of the English Language, New York, $1985,{ }^{20} 1994$.

Quirk idr. 1993 = R. Quirk idr., A University Grammar of English, Hong Kong, $1973,{ }^{27} 1993$.

Simeon 1969 = Rikard Simeon, Enciklopedijski rječnik lingvističkih naziva 1, Zagreb: Matica hrvatska, 1969.

SLP 2000 = Ada Vidovič Muha, Slovensko leksikalno pomenoslovje: Govorica slovarja, Ljubljana: Znanstveni inštitut Filozofske fakultete, 2000.

SP 2001 = Slovenski pravopis, Ljubljana: Založba ZRC, ZRC SAZU, 2001.

SS 1976 = Jože Toporišič, Slovenska slovnica, Maribor: Obzorja, 1976, ${ }^{4} 2000$.

SSB 1988 = Ada Vidovič Muha, Slovensko skladenjsko besedotvorje ob primerih zloženk, Ljubljana: Znanstveni inštitut Filozofske fakultete - Partizanska knjiga, 1988.

SSKJ = Slovar slovenskega knjižnega jezika 1-5, Ljubljana: DZS, 1970-1991.

Švedova idr. 1980 = N. Ju. Švedova idr., Russkaja grammatika 2: Sintaksis, Moskva: Nauka, 1980. 
Vidovič Muha 1984 = Ada Vidovič Muha, Nova slovenska skladnja J. Toporišiča, Slavistična revija 32 (1984), št. 2, 142-155.

Vidovič Muha 2000 = Ada Vidovič Muha, Čas v besedi: Tipologija leksikalne večpomenskosti, XXXVI. seminar slovenskega jezika, literature in kulture, Ljubljana: Filozofska fakulteta, 2000, 85-109.

Žele 2000 = Andreja Žele, Tipologija poved(kov)ne rabe v Slovarju slovenskega knjižnega jezika, Jezikoslovni zapiski 6 (2000), 57-65.

Žele 2001 = Andreja Žele, Tipologija pridevniške vezljivosti, Jezikoslovni zapiski 7 (2001), 163-195.

Žele 2003 = Andreja Žele, Slovarska obravnava povedkovnika, Jezik in slovstvo 48 (2003), št. 2, 3-15.

The Predicative, or the Predicative Role of Words

\begin{abstract}
Summary
The Slovenian predicative (povedkovnik) is a syntactic category because it is merely a semantic-structural component of a predicator with one single fixed syntactic role. The expression predicative (povedkovnik) seems suitable as well (cf. nedoločnik 'infinitive', namenilnik 'supine'), and hence the abbreviation povdk., which is already in use. As the main semantic-structural distinctive feature/component the primary function of a predicative (i.e., a predicative category) is only typical of a limited group of very heterogeneous (in terms of their development) group of lexemes (usually without a determined word class), such as v̌̌eč 'like', žal 'sorry', mraz 'cold', treba 'necessary', škoda 'a pity, a waste', dolgčas 'bored', prav 'right', lahko 'eas(il)y'. From the lexicographic perspective, only the entities listed above can be given the status of main entries with the label povdk., whereas other lexemes with a sufficiently frequent or specific secondary predicative function might be treated as subentries, also carrying the label povdk.
\end{abstract}

